\title{
Gerásimo Sosa y la cerámica de Chulucanas
}

\author{
Esteban Puig T. \\ Academia Nacional de la Historia del Perú
}

Una de las maravillas más notorias y famosas del Perú, aunque a veces no lo parezca, se encuentra en la cerámica. Constituye por sus formas y colores un legado artístico y cultural sorprendente, tanto en las piezas ceremoniales como en la cerámica utilitaria que también se ofrecía en las tumbas. Muchas piezas valiosas se exhiben en museos y universidades de todo el mundo. Arqueólogos peruanos, eximios por su tesón y eficiencia en investigar el legado cultural de las múltiples culturas ancestrales del Perú, sacaron del subsuelo valiosas cerámicas caracterizadas por su finísima contextura, sus formas, colores, dibujos, pinturas, escenas rituales, la fauna y la flora, la pesca y la caza, danzas, comidas y bebidas.

La cerámica más espectacular quizá sean las piezas de las culturas Nasca y Moche, admiradas por las vasijas decoradas a pincel pintadas con escenas alucinantes. De hecho, gracias a sus pinturas en las vasijas, podemos apreciar la abundancia de manifestaciones, hechos y sucesos de la vida cotidiana y de las grandes ceremonias rituales y funerarias de los mochicas, en especial, que componen una auténtica enciclopedia temática de alto valor gráfico y documental. No hay en toda América una iconografía pictórica y escultórica del vivir y del sentir de un pueblo, como la que nos legaron nuestros antepasados mochicas.

En la hacienda Pabur, a 50 kilómetros al este de la ciudad de Piura, floreció la cultura Vicús, que ofrece una fuerte y organizada civilización de intensa esencia regional. A pesar de lo que se ha dicho de ella, que es mucho, aún permanece en el enigma la procedencia de los hombres y las mujeres que vivieron en torno al cerro Vicús. ¿Provendrán de la costa ecuatoriana, de la sierra o del área central andina? ¿Cómo eran? ¿Qué mentalidad reflejan? ¿Cuáles fueron sus creencias, sus ritos, sus tradiciones y costumbres? Con todo, algo concreto se sabe de ella: que hubo señoríos que eran más reinos que señoríos, que se dio una clara diferenciación de lo religioso con lo civil; que surgieron centros administrativos y ceremoniales; que florecieron las artes; que la cerámica fue única por su acabado y modelado; que la metalurgia alcanzó altos niveles de técnica y belleza.

El descubrimiento de tumbas de esta cultura en 1963 ha permitido conocer su producción cultural, en la que destacan la cerámica de formas y características curiosas. También ha hecho posible que la producción de cerámica artesanal

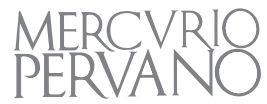


tradicional en pueblos como Simbilá se transformara totalmente y se convirtiera en un importante producto de exportación, y una gran parte de ese éxito se debe al ceramista Gerásimo Sosa.

Nacido en Piura, en 1953, este artesano chulucanense es un ceramista primoroso, creativo y artista de la plasticidad, que tiene en su haber obras de arcilla de una creatividad y belleza admirables, estupendas. Y parte de su éxito ha sido haber sabido reconocer y revalorar las técnicas ancestrales de la cultura Vicús: el paleteado, el modelado, la técnica del negativo, el diseño, los colores... Su empeño por desarrollar y enseñar las técnicas, en beneficio de la identidad regional a los artesanos y la población, ha cosechado muchos frutos.

Tiene en su haber innumerables exposiciones dentro y fuera del Perú. Obtuvo, por ser única en el Perú, el título de producto de bandera para la cerámica chulucanense; también consiguió que se aprobara la Ley del Artesano y Productividad Artesanal. En el 2000 fue reconocido como amauta de la artesanía peruana.

Fue descubierto y promovido por la religiosa hermana Gloria Joyce, quien lo motivó en su talento y a seguir las técnicas ancestrales de hace dos mil años para producir sus propias piezas. Su trabajo ha experimentado un proceso de evolución creativa admirable. La Universidad de Piura se enorgullece de contar con la colección más completa de sus primeras creaciones hasta la actualidad, en las que se puede descubrir el itinerario temático y creativo-artístico conectado con el hombre, la tierra y el arte piuranos.

Conseguimos una serie de obras de su talento y de su finura artística asombrosa. No es un elogio de por sí rebuscado para ensalzar las ventajas y ventas de sus productos. Lo que sí deseo es poner en vitrina los valores creativos y bellos de este hombre, sencillo y recto, que con sus obras ha dado al Perú y al mundo conciencia de lo que es un artesano del barro, del fuego, del aire y de la naturaleza. Quien ha visto sus innumerables piezas se queda removido por el admirable hechizo y belleza que dispensan. En el 2010 fue reconocido con el premio Campodónico en la modalidad de actividad profesional destacada: "Por su meritorio aporte como creador, productor y promotor de la cerámica de Chulucanas, a partir de la revaloración de las técnicas ancestrales de la cultura Vicús que han fortalecido la identidad en su comunidad y en la región norte, trascendiendo más allá de nuestras fronteras".

Tuve la oportunidad de verlo muchas veces en su taller de Chulucanas, esa emblemática ciudad de alfareros y artífices ceramistas. Era increíble apreciar con los ojos y la mente la variedad, la forma y el colorido que daba a sus ceramios. Impactante. He pasado ratos contemplando la gama de su producción y, además, como profesor de antiguas civilizaciones peruanas, conocedor de toda la cerámica exhibida en los museos del Perú, que son muchos, puedo afirmar sin disonancias que no he visto ni en los ceramistas de Chulucanas -que lo tienen como maestro- nada parecido a lo que crea y recrea Gerásimo. 
El proceso y la creación de cerámicos es un don donde el hombre, la tierra y el arte se entretejen para crear una obra bella. El artista, por su espíritu creador, dignifica la materia, la libera de su pesadez y la eleva a la categoría de belleza. He ahí el auténtico arte. Mis alumnos de la Universidad de Piura conocen muy bien las lecciones que les daba referentes al proceso de la elaboración de la cerámica. Lo que les exponía -lo digo con orgullo- lo aprendí de Gerásimo. El barro en las manos del alfarero es dúctil, suave, "caelón", "celoso", expresiones típicas de los alfareros piuranos para expresar cómo es de maleable y dócil. Por eso encantaba ver cómo lo modelaba sin brusquedades, con cariño, con sutil afecto como una madre que acaricia, con ternura, el rostro de su hijo pequeño. Con leve susurro decía: "hay que sentir al barro" mientras, fija su mirada en él, modelaba formas y figuras. La obra se parece al artista. En Gerásimo el barro deleznable, informe cobra vida, y con sus manos -la herramienta por excelencia del ceramista- va logrando darle la forma ideada. Gerásimo descubrió el arte y la técnica del ceramio mirando, jadmirado!, las obras de sus antepasados, eximios ceramistas: vicús, tallanes, mochicas, chimús e incas, especialmente los primeros. Se preguntaba: ¿qué clase de barro usaban, cómo modelaban, qué forma tenía la base del cerámico, el gollete, el pico, el asa? ¿Cómo lograban la textura finísima, perfecta de los 'huacos ofrendas' y de los huacos 'silbadores'? Gusta, asimila y elabora, con maravillosa continuidad, la chispa de la belleza, la inspiración y visión de su relevante abolengo. No son copias. Él le da un toque propio y distintivo. Gerásimo ha vencido la materialidad de lo perecedero y ha insuflado un halo de belleza trascendente.

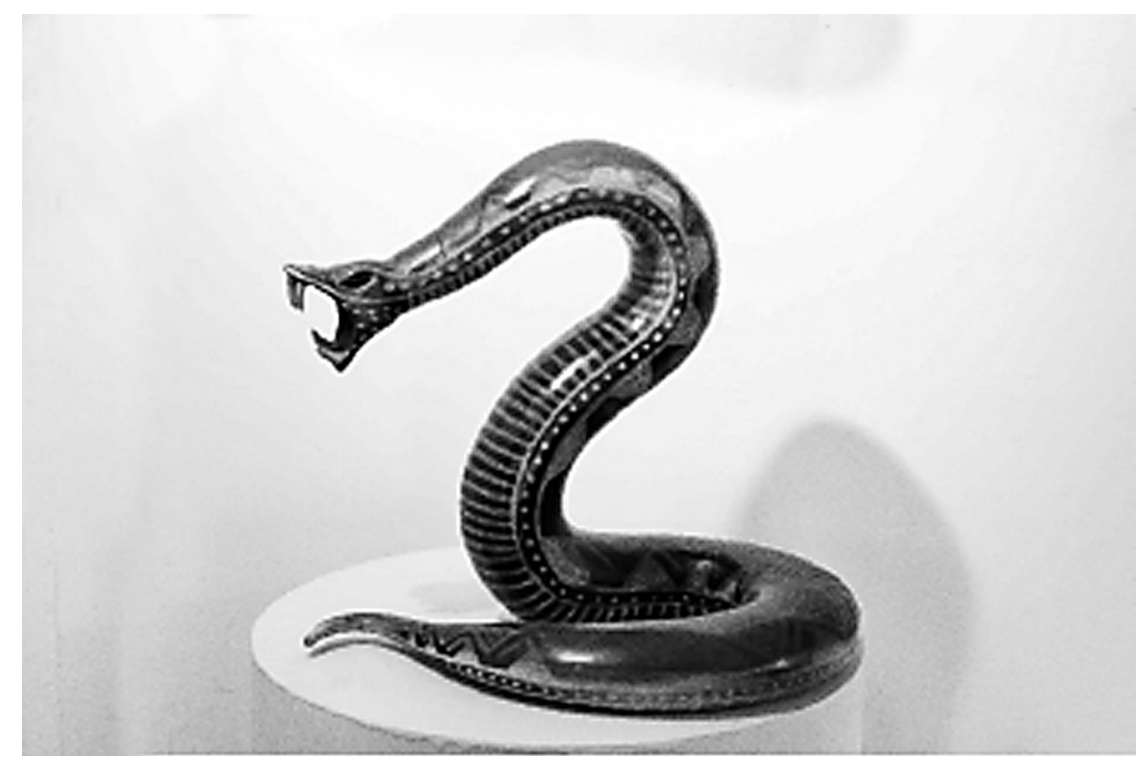

Figura 1. Gerásimo Sosa Alache, "Serpiente". Colección Biblioteca Udep. 
Gerásimo suele presentar los ceramios con estilizadas formas, finas y elegantes. Nada se escapa a su percepción simple y luminosa de la belleza que hay en lo más sencillo, en lo humilde, lo de cada día, lo ordinario: el gozo por las cosas, las plantas, los algarrobos, los animales, las aves... Todo su entorno físico, toda la gama de la fauna y flora piuranas la plasma con inusitado vigor y frescura. Los rostros, los rasgos, las facciones de los hombres y las mujeres son piuranos. Inconfundibles. Pasan ante nuestros ojos animales mitológicos, pletóricos, con alas desplegadas; chilalos silbando; un diminuto colibrí simpatiquísimo revolotea sobre una flor; garzas que levantan, curiosas, sus cabezas con las patas en posición de danza; un pajarito que intenta, desesperadamente, romper la cáscara en el que ha vivido hasta ahora; la temible 'macanche', la serpiente venenosa -a mi entender una de las más bellas obras de Gerásimo-, retadora, a punto de ataque, con la boca abierta mostrando sus temibles colmillos..., ¡terrorífica! Es una obra de arte, de armonía, de precisión, de forma y expresión inigualables. Y van sucediéndose patos, búhos, sabandijas, pacazos y soñas, figuras humanas con su vestimenta de pantalón de 'oreja' y sombrero 'a la pedrada'; rostros sonrientes, pletóricos, ufanos, llenos de vida, alegres por el gozo de vivir.

En las obras en las que plasmó al labrador, al 'paisa' y su mujer con los hijos son auténticos retratos de la vida y costumbre de su gente. Los piuranos los reconocen inmediatamente. No son simples labriegos, con sus palas y mantas. Son hombres y mujeres de carne y hueso, que vemos transitar por las calles y plazas del pueblo. Las mujeres tienen facciones tallanas, mochicas, chimús, de trenzas oscuras y prietas, con la manta acurrucando a su niñito... Eso sí, busquen en sus atuendos los pantalones de lana negra, con una abertura junto a los pies descalzos y arremangados por debajo de la rodilla; miren bien el sombrero 'a la pedrada', este toque vanidoso que le da al ponérselo. No verán en las mujeres las múltiples faldas puneñas en arrebolado vaivén. Eso no es piurano.

Gerásimo no hace esculturas, sino ceramios. El paisa piurano sale con su sombrero de jipijapa, en camisa, con la alforja fiambrera, la limeta de calabaza donde lleva la chicha "pa' fresquiarse". Con una mano sostiene la alforja que lleva en el hombro y con la otra el inseparable machete. ¡Qué maravilla ver al 'paisa' con su 'piajeno' con las alforjas al hombro cargadas de sueños y esperanzas. No lleva poncho. El poncho es para el frío de la sierra que en la costa sería absurdo y vergonzoso llevarlo. Lo asombroso es que todos estos personajes tienen el cuerpo redondo, henchido, pletórico, de botijo. No hay ni pecho ni cintura. Simplemente es un 'huaco'. Esa es la impronta más sobresaliente de sus personajes, que lejos de aparecer toscos y ridículos son todo lo contrario. Le dan un aire, una gracia sorprendente de vida, de gozo, de buen hacer, buen decir y buen andar.

De un tiempo a esta parte, Gerásimo ha creado una serie de ceramios de porcelana monocromáticos (blanco y negro) de formas elegantes, muy bellos y muy del gusto actual para adorno del hogar en figura de floreros, macetas, platos,

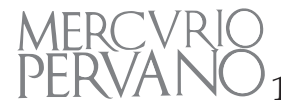


jarras, cántaros, tachos, tinajeras chicheras y también figuras más estilizadas. Su forma se parece a los objetos confeccionados con loza, de diversos colores y estilos. En los de Gerásimo abundan las líneas ondulantes, la vista de colores alternados con precisión y arte, molduras, listones, cenefas, arabescos, rizos, relieves que hacen del ceramio una obra de belleza y armonía sin par. El placer que causa ver sobre la repisa, en la mesa o en una parte de la casa un ceramio de Gerásimo es como percibir un grito estético que surge, triunfante, de sus cántaros. El esplendor de lo bello retrata la maestría de nuestro ceramista. Se espera, aún, mucho de él, pues su inspiración, su creatividad y sus dotes de artista mostrarán todavía más facetas de este gran ceramista.

No tengo ninguna duda al respecto: Gerásimo Sosa es un artista, un ceramista como pocos, artesano maravilloso, hombre cabal, sensible, costumbrista de primera y piurano cien por cien. Sabe imbricarse con el hombre, la tierra y el arte. Un artista así hay que conocerlo en sus obras que definen el talante del ceramista, la profesionalidad del artesano y la belleza telúrica del piurano. 